\title{
Eddy current testing system for bottom mounted instrumentation welds
}

\author{
Noriyasu Kobayashi ${ }^{*}$, Souichi Ueno ${ }^{1}$, Naotaka Suganuma ${ }^{1}$, Tatsuya Oodake ${ }^{2}$, Takeshi Maehara ${ }^{3}$, Takashi Kasuya ${ }^{3}$, \\ and Hiroya Ichikawa ${ }^{4}$ \\ ${ }^{1}$ Power and Industrial Systems Research and Development Center, Toshiba Corporation, 8, Shinsugita-cho, Isogo-ku, Yokohama \\ 235-8523, Japan \\ ${ }^{2}$ Power and Industrial Systems Research and Development Center, Toshiba Corporation, 1, Komukaitoshiba-cho, Saiwai-ku, \\ Kawasaki 212-8581, Japan \\ ${ }^{3}$ Keihin Product Operations, Toshiba Corporation, 2-4, Suehiro-cho, Tsurumi-ku, Yokohama 230-0045, Japan \\ ${ }^{4}$ Isogo Nuclear Engineering Center, Toshiba Corporation, 8, Shinsugita-cho, Isogo-ku, Yokohama 235-8523, Japan
}

Received: 19 June 2015 / Received in final form: 18 August 2015 / Accepted: 27 August 2015

Published online: 05 December 2015

\begin{abstract}
The capability of eddy current testing (ECT) for the bottom mounted instrumentation (BMI) weld area of reactor vessel in a pressurized water reactor was demonstrated by the developed ECT system and procedure. It is difficult to position and move the probe on the BMI weld area because the area has complexly curved surfaces. The space coordinates and the normal vectors at the scanning points were calculated as the scanning trajectory of probe based on the measured results of surface shape on the BMI mock-up. The multi-axis robot was used to move the probe on the mock-up. Each motion-axis position of the robot corresponding to each scanning point was calculated by the inverse kinematic algorithm. In the mock-up test, the probe was properly contacted with most of the weld surfaces. The artificial stress corrosion cracking of approximately $6 \mathrm{~mm}$ in length and the electrical-discharge machining slit of $0.5 \mathrm{~mm}$ in length, $1 \mathrm{~mm}$ in depth and $0.2 \mathrm{~mm}$ in width given on the weld surface were detected. From the probe output voltage, it was estimated that the average probe tilt angle on the surface under scanning was $2.6^{\circ}$.
\end{abstract}

\section{Introduction}

Eddy current testing (ECT) techniques to detect a defect, especially a stress corrosion cracking (SCC), on a reactor vessel (RV) and reactor internals have been developed as one of the surface inspection methods for nuclear power plants [1-7]. As a part of maintenance methods for the RV and reactor internals, laser peening and underwater laser beam welding techniques to prevent and repair from the SCC have been developed [8-11]. These inspection and maintenance techniques can contribute to shorten their work period, including the initial set-up because it is possible to work underwater without draining the reactor coolant. In order to provide faster services, the defect detection capability of the ECT probe using the cross coil has been estimated for the inspection before and/or after the underwater laser beam welding for the dissimilar metal welding area at the RV nozzle in pressurized water reactors (PWRs) [12-14]. The ECT

*e-mail: noriyasu.kobayashi@toshiba.co.jp system, including the small ECT probe and the probe moving equipment based on the portable laser peening system, has been developed for the bottom mounted instrumentation (BMI) weld area in PWRs [15]. In this development, the SCC detection capability of the system was demonstrated by moving the probe on the area of $10 \mathrm{~mm} \times 6 \mathrm{~mm}$ of the BMI mock-up [15].

More precise probe action control is required to move the probe on the whole BMI weld area because the area has complexly curved surface and the narrow spaces. We measured the surface shape of weld area using the laser displacement meter and made the scanning trajectory of the probe based on the shape measurement data of the complex surface. As a BMI mock-up test, the ECT probe was automatically moved on the whole BMI weld area by the multi-axis robot. From the test results, we evaluated the defect detection capability of the ECT system and the probe tilt angle on the weld surface under scanning. In this paper, we describe the procedure of BMI mock-up test; the results of measuring weld surface shape and defect detection tests. 


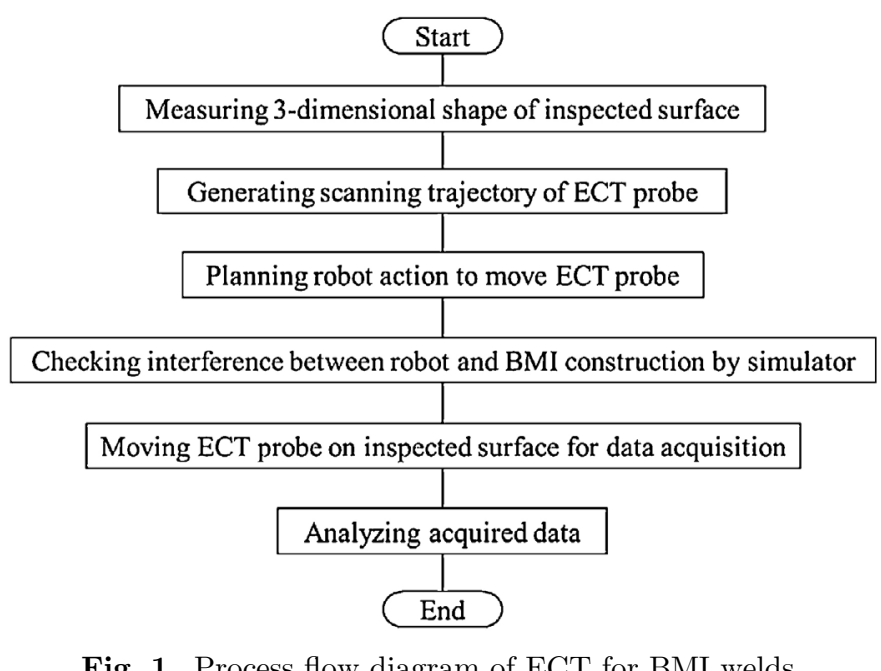

Fig. 1. Process flow diagram of ECT for BMI welds.

\section{Weld surface shape measurement}

\subsection{Procedure of BMI mock-up test}

A process flow diagram of an ECT for BMI welds is shown in Figure 1. The three-dimensional shape of inspected weld surface was measured in order to generate the precise scanning trajectory of ECT probe. After generating the trajectory, the action of multi-axis robot, which moves the probe along the scanning trajectory on the weld surface, was planned and checked for the interference between the robot and the BMI mock-up. The probe was moved on the whole BMI weld area by the robot to acquire the ECT defect detection data. Finally, we analyzed the acquired data, including the signal processing for noise rejection and signal identification.

\subsection{Measurement of surface shape}

We measured the surface shape of the weld area on the BMI mock-up for generating the scanning trajectory of ECT probe. A half of weld area was the target for scanning by the ECT probe because the mock-up is axisymmetric. The measurement range of surface shape is the half side of weld area and within approximately $60 \mathrm{~mm}$ in radius centering on the BMI nozzle as shown in Figure 2. The sensor head of laser displacement meter (KEYENCE, LJ-G200) mounted on the multi-axis robot measured the three-dimensional surface shape in an approximately $0.5 \mathrm{~mm}$ interval at the points of approximately $60 \mathrm{~mm}$ from the center of nozzle within the measurement range. The sensor head rotated round trip half side around the nozzle. The laser spot size is $180 \mu \mathrm{m} \times 70 \mathrm{~mm}$. The base work distance is $200 \pm 48 \mathrm{~mm}$.

\subsection{Scanning trajectory of probe}

The space coordinates and the normal vectors at the scanning points as the scanning trajectory of ECT probe on welds were generated based on the measured results of weld surface shape on the BMI mock-up. The calculated results of the trajectory were shown in Figure 3. The blue range in Figure 3 is the measured surface shape. The red arrows indicate the calculated results of normal vector for determining the probe angles at the scanning points. The probe is set on the inspected surface, as the probe central axis is adjusted to coincide with the normal vector at each scanning point.

\subsection{Multi-axis robot}

The multi-axis robot, which moves the ECT probe, is shown in Figure 4. The robot has three translation axes and

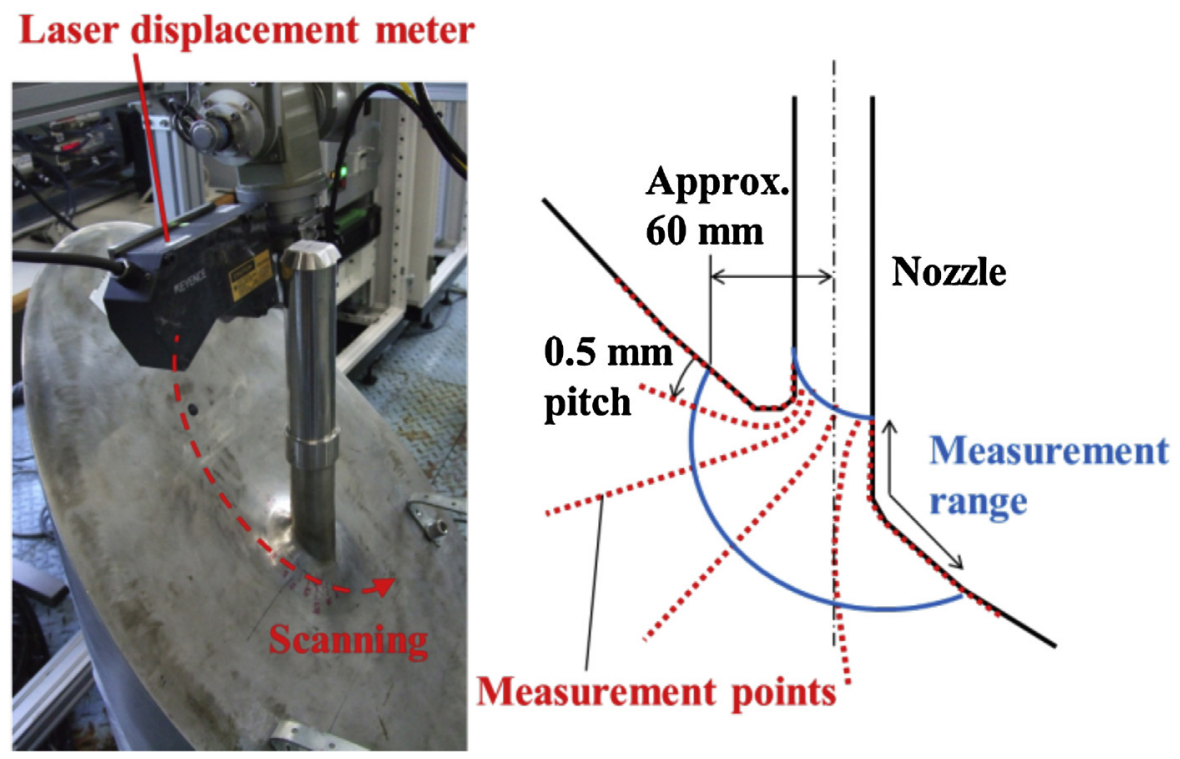

Fig. 2. Measurement of weld surface shape on BMI mock-up. 


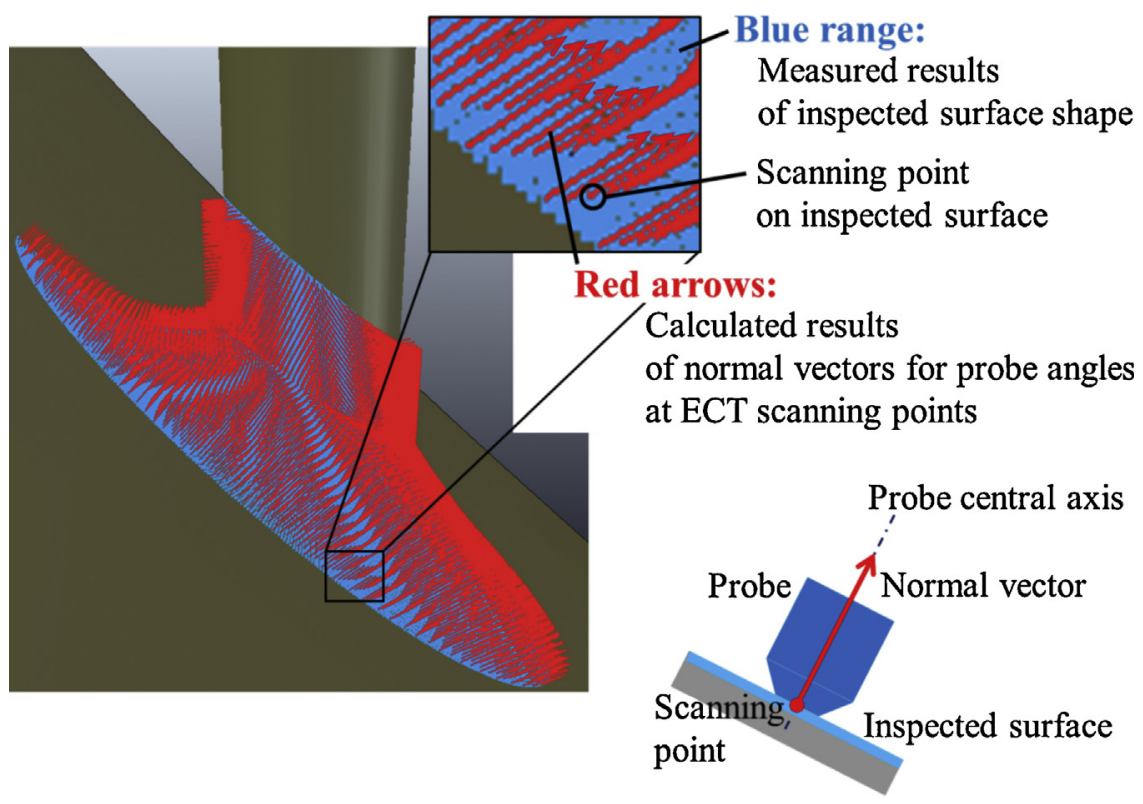

Fig. 3. Scanning trajectory of ECT probe.

four rotation axes. The probe was mounted on the end of the robot arm. Each motion axis position as a robot action corresponding to each scanning point was calculated by the inverse kinematic algorithm. After the two rotating motion axis positions were provided as the constant values, the other motion axis positions were led in the calculation. The probe-scanning trajectory shown in Figure 3 was divided into the three ranges (nozzle, J-welds and build-up welds)

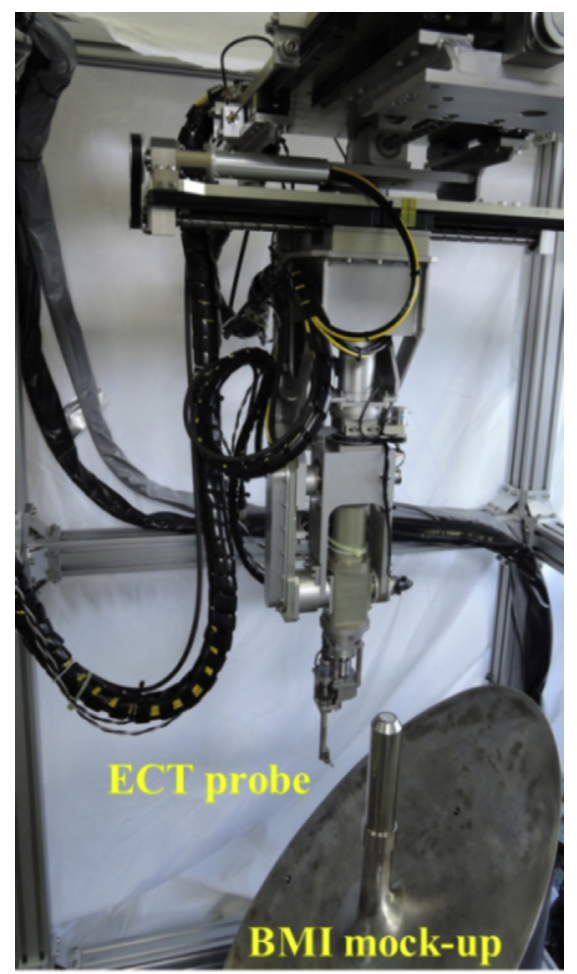

Fig. 4. Multi-axis robot. as shown in Figure 5. The three different algorithms for the three ranges were used to prevent from the interference between the robot and the BMI mock-up. It was confirmed not to interfere between the robot and the mock-up using the three-dimensional simulator before the mock-up test.

\section{Experimental apparatus and methods}

\subsection{ECT system}

A block diagram of the ECT system is shown in Figure 6 . This system consists of the ECT probe, the multi-axis robot, the robot controller, the ECT data acquisition system and the ECT data analysis system. The probe was moved to a start point of scanning manually. As soon as a scanning was started under the order from the robot controller, the ECT data acquisition system received the coordinate data of the start point from the controller and voltage signals from the probe. After the acquisition system paired the coordinate data with the voltage signals and saved them into a memory, the acquisition system sent an acquisition end signal at the start point to the controller. The controller automatically moved the probe to the next scanning point using the multi-axis robot based on the probe-scanning trajectory. These movements were repeated until the entire scanning is completed. The ECT data analysis system read the scanning coordinate data and the probe output signals, and conducted the signal processing and displayed the inspected results.

\subsection{BMI mock-up and scanning range}

A schematic of the BMI mock-up simulating the outermost nozzle at the bottom of RV is shown in Figure 7 [15]. The nozzle was fixed to the bottom of RV by a tungsten inert gas 


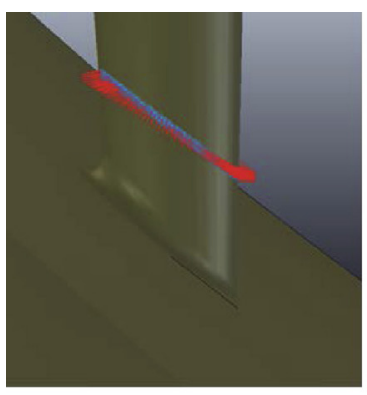

Nozzle

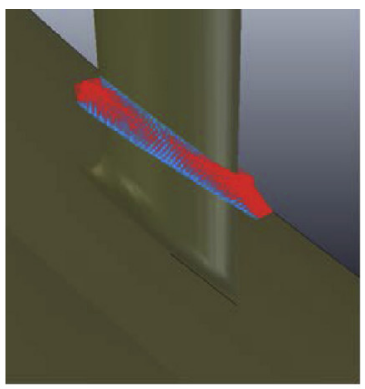

J-welds

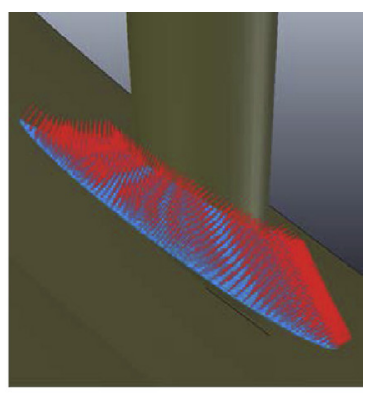

Build-up welds

Fig. 5. Divided scanning trajectories.

(TIG) welding. The surface of weld area was machined smoothly. Both the nozzle and the weld metal are made of alloy 600. Artificial and circumferential defects were given on the weld surface at the points of $10 \mathrm{~mm}$ from the outer surface of nozzle. The type and size of defects are described in Table 1. It was defined that the top of the mock-up is at $0^{\circ}$ in circumferential angle as shown in Figure 7 . The length of SCC shown in Table 1 is the value of indication on penetrant testing (PT).

The scanning range by the ECT probe is shown in Figure 8. The start point of scanning is on the outer surface of nozzle at $0^{\circ}$ in circumferential angle and approximately $3 \mathrm{~mm}$ above the J-weld. The probe was moved in less than $0.5 \mathrm{~mm}$ interval within the scanning range in a circumferential direction and made several round trips half side around the nozzle. An end point of scanning is on the buildup weld surface at $0^{\circ}$ in circumferential angle and approximately $40 \mathrm{~mm}$ from the center of nozzle. This scanning range includes the nozzle, the J-welds, the buildup welds and the artificial defects.

\subsection{Experimental and calibrating conditions}

The experimental and calibrating conditions are shown in Table 2. We used the developed ECT probe [15] that has small-sized cross coil and the higher directional

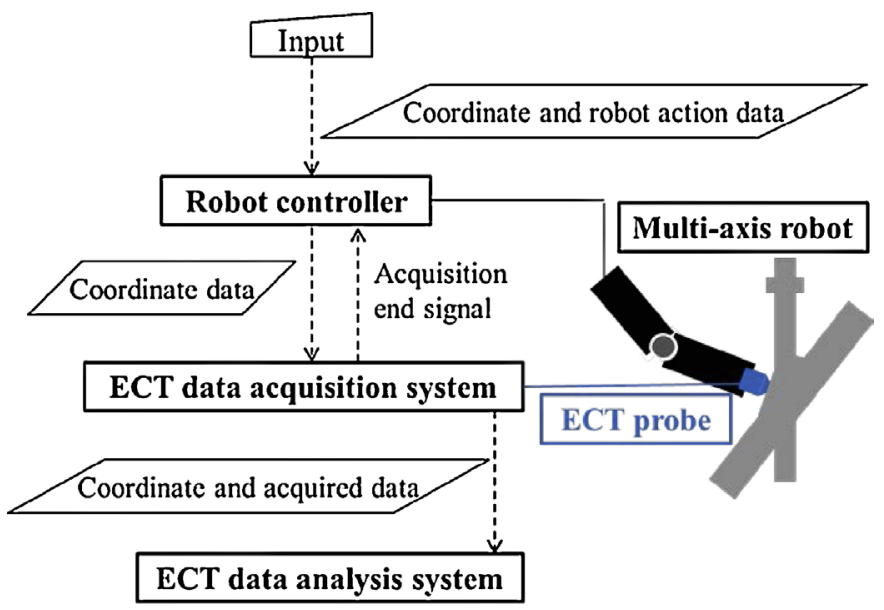

Fig. 6. Block diagram of ECT system. characteristics of magnetic field in the mock-up test. The diameter of the probe tip that has contact with an inspected surface is $3.4 \mathrm{~mm}$. The probe operated with the differential mode at the frequency of $250 \mathrm{kHz}, 500 \mathrm{kHz}$ and $1 \mathrm{MHz}$. The calibration block made of alloy 600 has an EDM slit of $80 \mathrm{~mm}$ in length, $1 \mathrm{~mm}$ in depth and $0.3 \mathrm{~mm}$ in width. The thickness of calibration block is $20 \mathrm{~mm}$. We calibrated the output voltage and the phase angle to $2 \mathrm{~V}$ and $90^{\circ}$ using this block in air, respectively.

\section{Experimental results of mock-up test}

The $\mathrm{C}$ scope images as seen through the signal processing for the absolute values of imaginary part of ECT output voltages at a frequency of $250 \mathrm{kHz}, 500 \mathrm{kHz}$ and $1 \mathrm{MHz}$ are shown in Figure 9. At a frequency of $250 \mathrm{kHz}$, the clear signals from the defect A (SCC), the defect B (EDM) and the defect $\mathrm{C}(\mathrm{EDM})$ were confirmed. It was considered that the signals from the defect $\mathrm{D}(\mathrm{EDM})$ and the defect $\mathrm{E}$ (SCC) were not detected because the volumes of the defect $\mathrm{D}$ and the defect $\mathrm{E}$ are smaller than those of the other

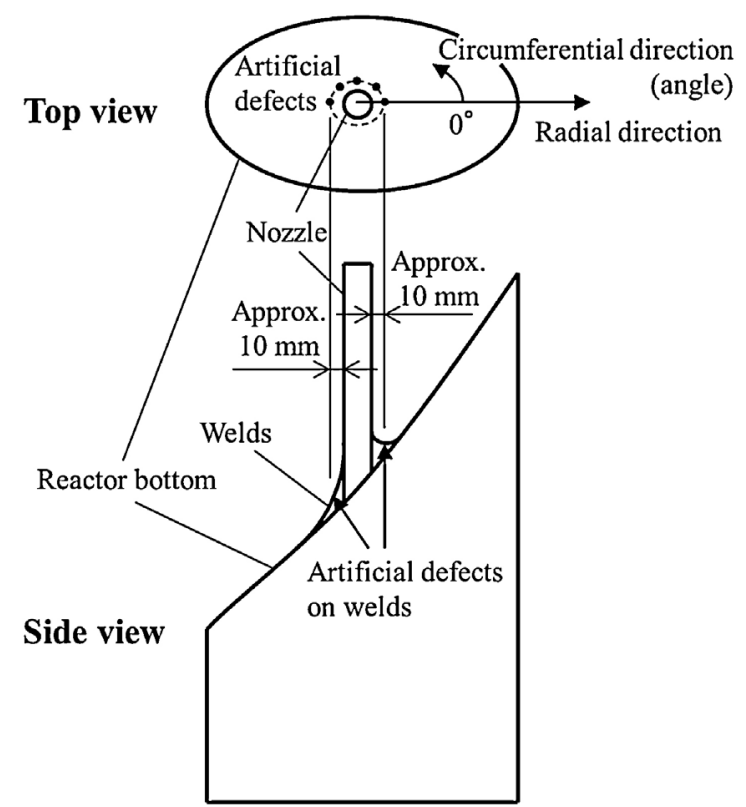

Fig. 7. Schematic of BMI mock-up [15]. 
Table 1. Artificial defects.

\begin{tabular}{|c|c|c|c|c|}
\hline Defect & Type & Length $(\mathrm{mm})$ & Depth $(\mathrm{mm})$ & Width $(\mathrm{mm})$ \\
\hline $\mathrm{A}$ & SCC & Approx. 6 & No data & No data \\
\hline B & EDM slit & 0.5 & 1.5 & 0.2 \\
\hline $\mathrm{C}$ & EDM slit & 0.5 & 1.0 & 0.2 \\
\hline D & EDM slit & 0.3 & 1.0 & 0.2 \\
\hline $\mathrm{E}$ & $\mathrm{SCC}$ & Approx. 3 & No data & No data \\
\hline
\end{tabular}

EDM: electrical-discharge machining; Approx.: approximately.

defects. The maximum output voltages of the detected defects were $0.93 \mathrm{~V}$ in the $\operatorname{defect} \mathrm{A}, 0.33 \mathrm{~V}$ in the defect $\mathrm{B}$ and $0.24 \mathrm{~V}$ in the defect $\mathrm{C}$. The ratio of maximum output voltages between the defects $\mathrm{B}$ and $\mathrm{C}$ was 1.4. This value was roughly equal to the ratio of the volumes between the defects $\mathrm{B}$ and $\mathrm{C}$ (1.5). On the other hand, the maximum output voltage of the noises was $0.25 \mathrm{~V}$. Under the following three assumptions:

a. the maximum output voltage from the defect is proportional to the defect volume;

b. the criterion for defect detection is that the signal to noise ratio is more than 2 ;

c. the ECT can detect the defect of $0.5 \mathrm{~mm}$ and more in depth,

it is estimated that the minimum EDM slit size that this ECT system can detect is approximately $2.3 \mathrm{~mm}$ in length, $0.5 \mathrm{~mm}$ in depth and $0.2 \mathrm{~mm}$ in width. The output voltage of the defect $\mathrm{E}$ was less than $0.125 \mathrm{~V}$. It was difficult to recognize the figure of the defect $\mathrm{E}$ visually. If the width of the defect $\mathrm{E}$ was $0.05 \mathrm{~mm}$, it is evaluated using the above assumption (a) that the depth of the defect $\mathrm{E}$ is less than $0.38 \mathrm{~mm}$. Although the length of the defect $\mathrm{E}$ is longer than the lengths of the other EDM slits, it is considered that the signal from the defect $\mathrm{E}$ was not detected because the width and depth are smaller than those of the other EDM slits.
Table 2. Experimental and calibrating conditions.

\begin{tabular}{ll}
\hline ECT probe & Cross coil \\
\hline Operation mode & Differential \\
Frequency $(\mathrm{kHz})$ & $250,500,1000$ \\
Atmosphere & In air \\
Calibration block & Alloy 600 (20 mm in thickness $)$ \\
EDM slit & \\
Length $(\mathrm{mm})$ & 80 \\
Depth $(\mathrm{mm})$ & 1 \\
Width $(\mathrm{mm})$ & 0.3 \\
Calibrated & 2 \\
Output voltage $(\mathrm{V})$ & 90 \\
Phase angle $\left({ }^{\circ}\right)$ & 9
\end{tabular}

The noises increased at higher frequencies. It was considered that the sensitivity of ECT probe for the change of surface shape was increased by the dense eddy current on the mock-up surface layer because of shallower skin depths at higher frequencies. The skin depth of alloy 600 at each frequency is shown in Table 3. The skin depth at each frequency is the same or less than the depth of the EDM slit given on the calibration block, $1.0 \mathrm{~mm}$. When a defect depth is the same or more than $1.0 \mathrm{~mm}$, a phase angle of a signal from a defect indicates the near-calibrated value, approximately $90^{\circ}$ or $-90^{\circ}$. Positive and negative values mean that directions of defects are mutually orthogonal. A phase angle of an eddy current lags to the direction of material depth [16]. Therefore, a phase angle of a signal from a defect may lag behind the calibrated value if a defect depth is less than $1.0 \mathrm{~mm}$. The measured phase angles of the signals from the defects (A, B and C) and the noises (F, G and $\mathrm{H}$ ) in Figure 9 are shown in Table 4. It was reasonable that the phase angles of the signals from the defects A, B and $\mathrm{C}$ were approximately $90^{\circ}$ or $-90^{\circ}$. It was considered that the noises $F$ and $G$ were caused by the change of
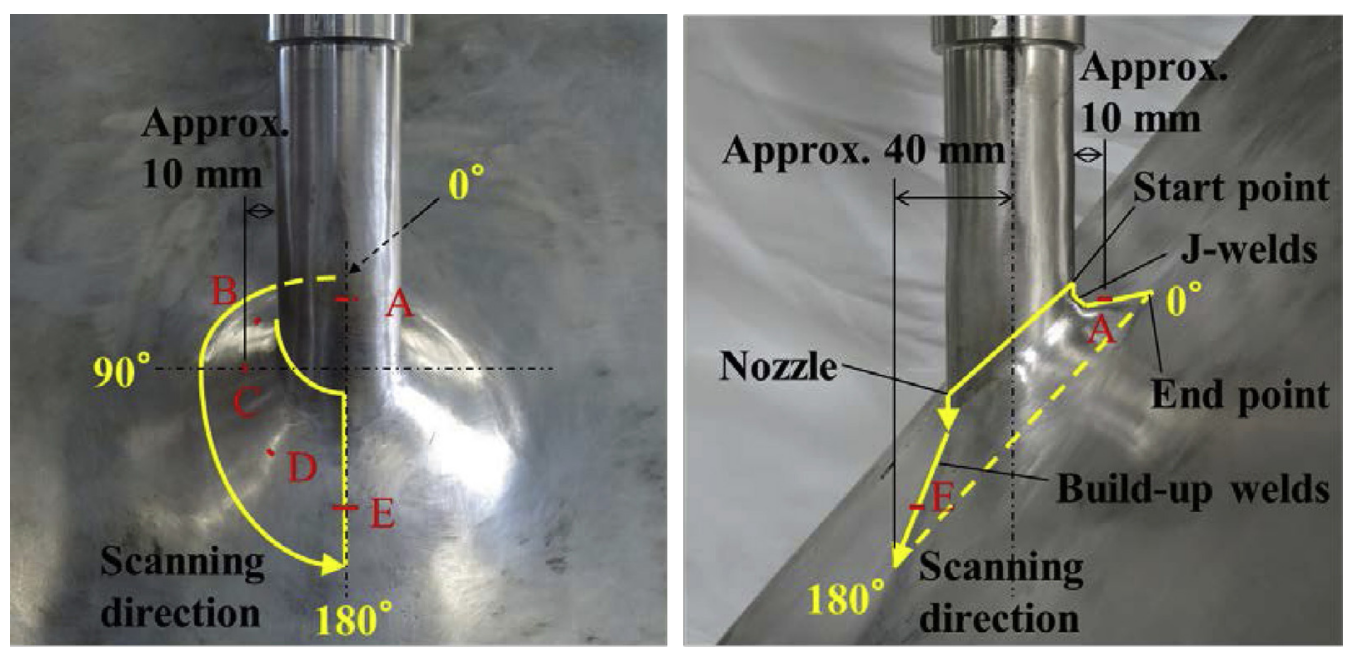

Fig. 8. ECT scanning range. 


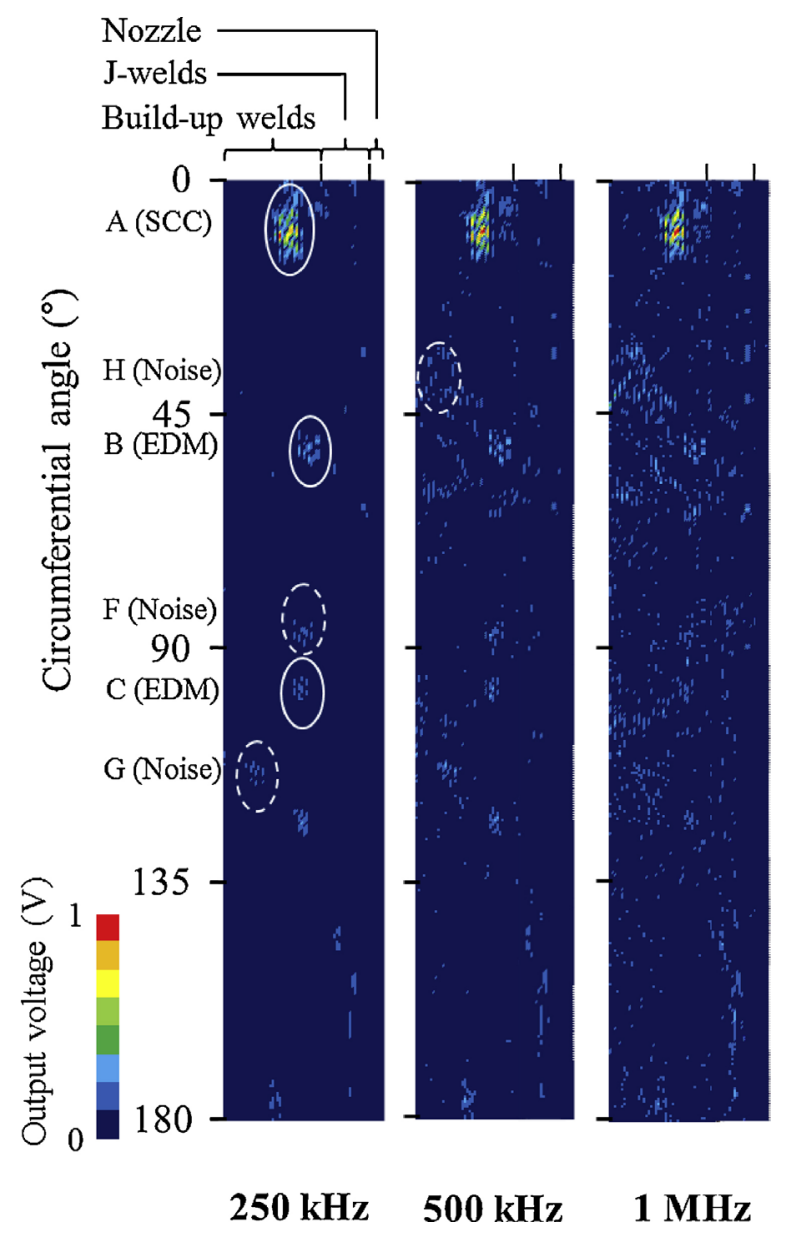

Fig. 9. C scope images of ECT output voltages.

surface shape more than $1.0 \mathrm{~mm}$ in depth because their phase angles were approximately $90^{\circ}$ or $-90^{\circ}$ as in the case of the defects $\mathrm{A}, \mathrm{B}$ and $\mathrm{C}$. The phase angle of noise $\mathrm{H}$ at the frequency of $500 \mathrm{kHz}$ was largely lagging behind $-90^{\circ}$. It was considered that the phase lag was observed at the frequency of $500 \mathrm{kHz}$ having the deeper skin depth because the depth of the surface shape change was much less than $1.0 \mathrm{~mm}$. The maximum output voltages from the defects are roughly equal at each frequency. It was estimated that the best frequency for the defect detection by the used ECT probe in this BMI mock-up test is $250 \mathrm{kHz}$.

\section{Discussions}

\subsection{Relationship between probe tilt angle and output voltage of single coil}

Because the probe tilt angle on the inspected surface influences a defect detection capability, the tilt angle under

Table 3. Skin depth of alloy 600 at each frequency.

\begin{tabular}{llll}
\hline Frequency $(\mathrm{kHz})$ & 250 & 500 & 1000 \\
Skin depth $(\mathrm{mm})$ & 1.0 & 0.71 & 0.50 \\
\hline
\end{tabular}

Table 4. Measured phase angles.

\begin{tabular}{llll}
\hline $\begin{array}{l}\text { Frequency }(\mathrm{kHz}) \\
\text { Phase angle }\left(^{\circ}\right)\end{array}$ & 250 & 500 & 1000 \\
Defect A & 99 & 91 & 80 \\
Defect B & 103 & 100 & 88 \\
Defect C & 90 & 87 & 83 \\
Noise F & 98 & 90 & 83 \\
Noise G & -95 & -94 & -112 \\
Noise H & Out of measure & -160 & -105 \\
\hline
\end{tabular}

scanning in this mock-up test could be roughly estimated. First of all, we investigated the relationship between the probe tilt angle on the flat surface specimen and the output voltage of single coil. The single coil means one of two coils that compose the cross coil and is more sensitive for the probe tilt angle than the differential mode of cross coil using the two coils. The area without the EDM slit of the calibration block shown in Table 2 was used as a flat surface specimen in this measurement. We defined the meaning of the probe tilt direction and angle as shown in Figure 10, respectively.

The measured result of the relationship between the probe tilt direction and the output voltage of single coil at a frequency of $500 \mathrm{kHz}$ is shown in Figure 11. The measured result at a frequency of $500 \mathrm{kHz}$ provided the smallest output voltage variation in the prior confirmation. The tilt angle is $9^{\circ}$ at constant angle. The output voltage was normalized by the value at the tilt direction of $0^{\circ}$ because the sensitivity of the ECT data acquisition system in this measurement was different from that in the mock-up test. The output voltage was constant within the variation of $15 \%$ by a change in the tilt direction. We measured the

\section{Top view}
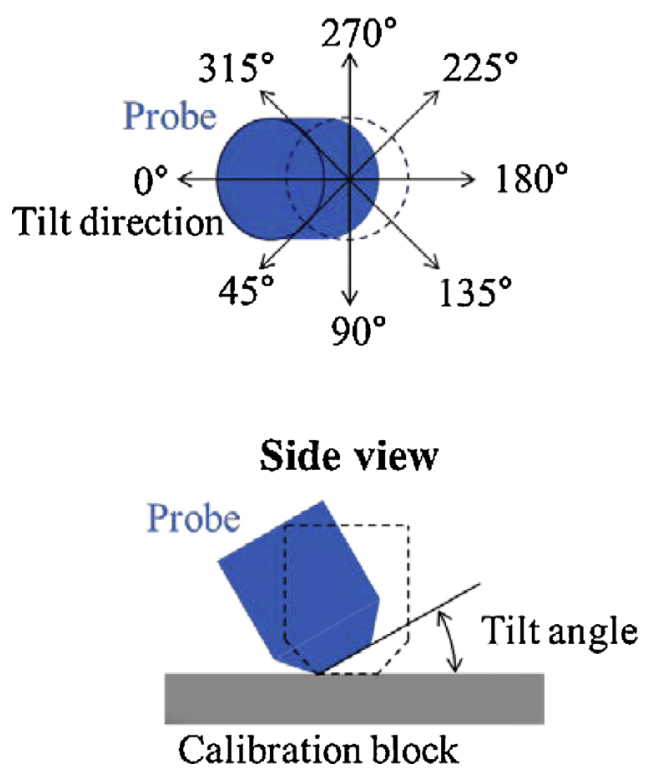

Fig. 10. Probe tilt direction and angle. 


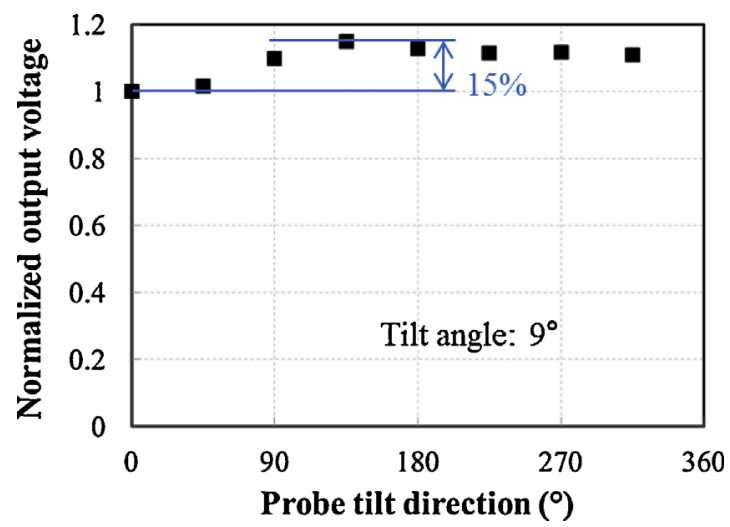

Fig. 11. Relationship between probe tilt direction and output voltage of single coil.

relationship between the probe tilt angle and the output voltage of single coil under the condition of $0^{\circ}$ in probe tilt direction. The sensitivity of the ECT data acquisition system in this measurement was the same as that in the mock-up test. The measured result of the relationship between the probe tilt angle and the output voltage of single coil at a frequency of $500 \mathrm{kHz}$ is shown in Figure 12. The tilt direction is $0^{\circ}$ at constant direction. The output voltage monotonically increased by the increase of tilt angle. We assumed that the output voltage is proportional to the tilt angle and used the function of linear approximation as an evaluation formula to estimate the tilt angle from the output voltage in the mock-up test.

\subsection{Estimation of probe tilt angle under scanning in mock-up test}

The output voltage of single coil was measured while moving the ECT probe on the J-welds of the BMI mock-up at a frequency of $500 \mathrm{kHz}$. The probe tilt angle under scanning from the measured output voltage could be roughly estimated using the evaluation formula as described previously. The estimated probe tilt angle is shown in Figure 13. The average and the maximum angles were $2.6^{\circ}$ and $8.5^{\circ}$, respectively. As the photographs show in

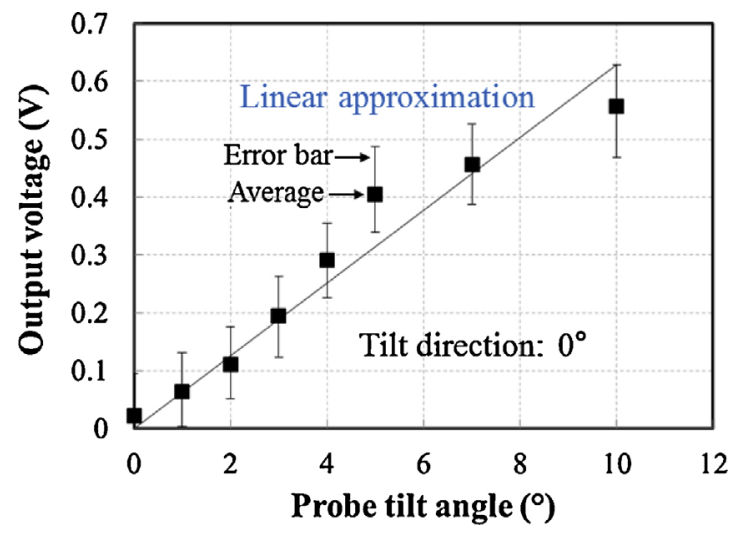

Fig. 12. Relationship between probe tilt angle and output voltage of single coil.

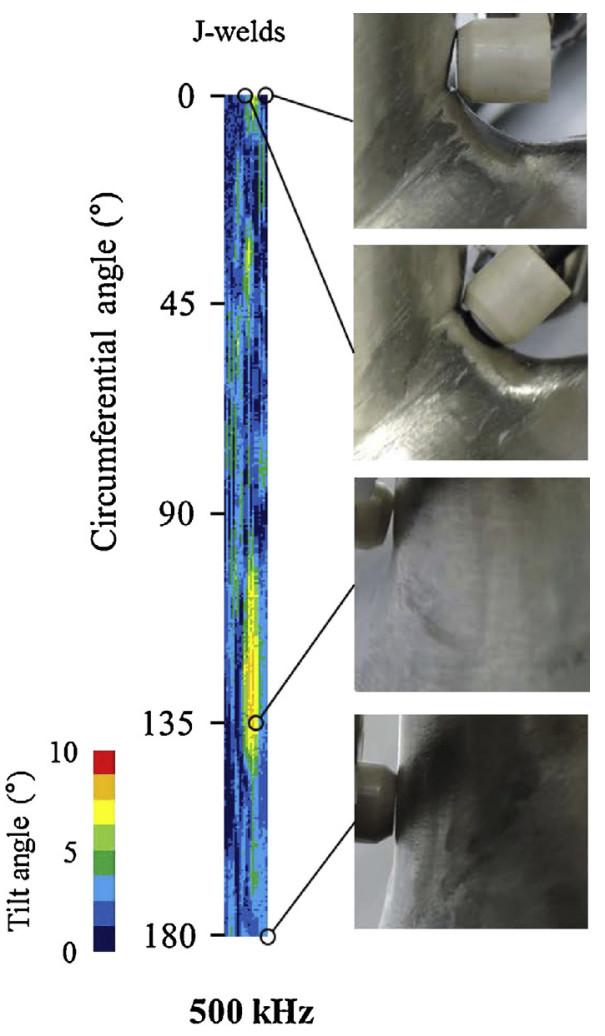

Fig. 13. Estimated probe tilt angles under scanning on J-welds of BMI mock-up.

Figure 13, the probe came into contact with the surfaces of J-welds on most of the scanning range. Our goal for the probe tilt angle is within $3^{\circ}$ on all the scanning range because it was previously confirmed that the sensitivity of this developed ECT probe for the machined slit of $0.5 \mathrm{~mm}$ in depth and $0.4 \mathrm{~mm}$ in width decreased nearly $1 \mathrm{~dB}$ when the probe tilt angle increased from $0^{\circ}$ to $3^{\circ}$ [15]. It was considered that the cause of tilt angle of more than $3^{\circ}$ on the partial scanning range is the accuracy of installation position between the multi-axis robot and the BMI mockup. The highly accurate measurement and the correction of installation position are the action assignments for the inspection of actual plant.

\section{Conclusions}

The ECT for the whole weld area on the BMI mock-up was demonstrated using the developed ECT system and procedure in order to verify the defect detection capability for the BMI welds. The surface shape of weld area on the BMI mock-up was measured for generating the scanning trajectory of ECT probe. The space coordinates and the normal vectors at the scanning points as the scanning trajectory were calculated based on the measured results of weld surface shape. Each motion-axis position of the multiaxis robot corresponding to each scanning point was calculated by the inverse kinematic algorithm. The BMI mock-up test was performed using the developed ECT probe with the cross coil in the differential mode. The 
artificial SCC and EDM slits given on the build-up weld area were detected in the mock-up test. From the result of detecting defects, it is shown that this ECT system can detect a defect of approximately $2.3 \mathrm{~mm}$ in length, $0.5 \mathrm{~mm}$ in depth and $0.2 \mathrm{~mm}$ in width as the defect detection capability for the BMI welds. It was estimated that the average and the maximum probe tilt angles were $2.6^{\circ}$ and $8.5^{\circ}$, respectively. The highly accurate measurement and the correction of installation position between the multiaxis robot and the inspected BMI for controlling the probe tilt angle are the action assignments for the actual use.

\section{References}

1. T. Kasuya, T. Uchimoto, T. Takagi, H. Huang, Simulation of Shroud Inspection based on Eddy Current Testing, Maintenology 3, 51 (2004)

2. A.L. Hiser Jr. Cracking in Alloy 600 Penetration Nozzles - A Regulatory Perspective, in Proceedings of the 12th International Conference on Nuclear Engineering (ICONE12), ICONE12-49226, Arlington, USA, 2004 (2004)

3. W. Bamford, J. Hall, A Review of Alloy 600 Cracking in Operating Nuclear Plants Including Alloy 82 and 182 Weld Behavior, in Proceedings of the 12th International Conference on Nuclear Engineering (ICONE12), ICONE12-49520, Arlington, USA, 2004 (2004)

4. L. Chatellier, S. Dubost, F. Peisey, B. Richard, L. Fournier, Taking Advantage of Signal Processing Techniques for the Life Management of NPP Components, in Proceedings of the ASME 2006 Pressure Vessels and Piping Conference (PVP2006), PVP2006-ICPVT-11-93313, Vancouver, Canada, 2006 (2006)

5. Z. Chen, L. Janousek, N. Yusa, K. Miya, A Nondestructive Strategy for the Distinction of Natural Fatigue and Stress Corrosion Cracks Based on Signals from Eddy Current Testing, J. Press. Vessel Technol. 129, 719 (2007)

6. P. Anderle, L. Skoglund, R.S. Devlin, J.P. Lareau, H. Lenz, D. E. Seeger Jr., F.G. Whytsell, Reactor Vessel Head Penetration Inspection-Past, Present and Future, in Proceedings of the 8th International Conference on NDE in Relation to Structural Integrity for Nuclear and Pressurized Components, We.2.C.3, Berlin, Germany, 2010 (2010)
7. Z. Kuljis, B. Lisowyj, Characterizing Austenitic Materials and Nickel Alloys with Electro-Magnetic Imaging, in Proceedings of the ASME 2012 Pressure Vessels and Piping Conference (PVP2012), PVP2012-78502, Toronto, Canada, 2012 (2012)

8. Y. Kanazawa, M. Tamura, Underwater YAG Laser Welding Technique, Toshiba Review 60, 36 (2005)

9. M. Yoda, M. Tamura, Underwater Laser Beam Welding Technology for Reactor Vessel Nozzles of PWRs, Toshiba Review 65, 36 (2010)

10. I. Chida, K. Shiihara, T. Fukuda, W. Kono, M. Obata, Y. Morishima, Study on Laser Beam Welding Technology for Nuclear Power Plants, Transactions of the Japan Society of Mechanical Engineers Series B 78, 445 (2012)

11. I. Chida, T. Uehara, M. Yoda, H. Miyasaka, H. Kato, Development of Portable Laser Peening Systems for Nuclear Power Reactors, in Proceedings of the 2009 International Congress on Advances in Nuclear Power Plants (ICAPP'09), ICAPP09-9029, Tokyo, Japan, 2009 (2009)

12. N. Kobayashi, T. Kasuya, S. Ueno, M. Ochiai, Y. Yuguchi, C. S. Wyffels, Z. Kuljis, D. Kurek, T. Nenno, Utility Evaluation of Eddy Current Testing for Underwater Laser Beam Temperbead Welding, in Proceedings of the 8th International Conference on NDE in Relation to Structural Integrity for Nuclear and Pressurized Components, We.2.B.2, Berlin, Germany, 2010 (2010)

13. S. Ueno, N. Kobayashi, T. Kasuya, M. Ochiai, Y. Yuguchi, Defect Detectability of Eddy Current Testing for Underwater Laser Beam Welding, in Proceedings of the 19th International Conference on Nuclear Engineering (ICONE19), ICONE19-43658, Osaka, Japan, 2011 (2011)

14. N. Kobayashi, T. Kasuya, S. Ueno, M. Ochiai, H. Ichikawa, Feasibility Assessment of Eddy Current Testing in Underwater Laser Beam Welding, Journal of the Japanese Society for Non-Destructive Inspection 61, 475 (2012)

15. N. Kobayashi, S. Ueno, I. Chida, M. Ochiai, T. Fujita, H. Ichikawa, Development of Eddy Current Testing System for Bottom-Mounted Instrumentation Nozzle in Reactor Pressure Vessel, Maintenology 13, 106 (2014)

16. H.B. Libby, Introduction to Electromagnetic Non-destructive Test Methods (Wiley-Interscience, 1971)

Cite this article as: Noriyasu Kobayashi, Souichi Ueno, Naotaka Suganuma, Tatsuya Oodake, Takeshi Maehara, Takashi Kasuya, Hiroya Ichikawa, Eddy current testing system for bottom mounted instrumentation welds, EPJ Nuclear Sci. Technol. 1, 4 (2015) 